\title{
Simulation on Equivalence between Layered Space Plates and Homogeneous Steel Impacted by a Tungsten Sphere \\ Ran XIONG ${ }^{1, a}$, Bing ZHANG ${ }^{1}$, Tongjun $X^{1}$ \\ ${ }^{1}$ No. 63981 Unit of PLA, 430311, China \\ aemail: Bxiongran@163.com
}

Keywords: a tungsten sphere; penetration; layered space plates; homogeneous steel; numerical simulation

\begin{abstract}
To research on the equivalent of perforating through layered space plates and homogeneous steel, based on the rule that the limit penetrating velocity, the penetration process of tungsten sphere into layered space plates and homogeneous steel was simulated with LS-DYNA finite element code, the numerical results corresponded well to previous experimental observation. The expression between layered space plates and homogeneous steel impacted by a tungsten sphere was presented through analyzing the numerical results.
\end{abstract}

\section{Introduction}

In this paper a new optimal design of soccer robot control system which is based on mechanical analyses and calculations on the pressure and transmutation states of chip kick mechanics, this new control system with high precision for speed control and high dynamic quality. The penetration performance of fragment often is one of the important indicators of ammunition, and the penetration performance of fragment is often focused on the experiment and mechanism of a single homogeneous plate penetrated by fragment[1].For the structure of armor and missile, this paper focuses on layered space plates penetrated by fragment, and the protection level of layered space plates was equivalent by standard homogeneous steel. Numerical simulation is one of the main means of this kind of problem, It can greatly save the cost and shorten the research period by means of numerical simulation and the experimental correction[2]. Based on the principle of the equal ultimate velocity, the numerical simulation was used to the layered space plates and the homogeneous steel penetrated by the fragment through the finite element software LS-DYNA, and the equivalent relations of the layered space plates and the homogeneous steel target was preliminary study.

\section{Equivalence Principle}

The two kinds of principle can be chosen for the equivalent of the plate impacted by fragment: the ultimate velocity method and the residual penetration method. From the evaluation of the power of ammunition, the ultimate velocity method was chosen, from the evaluation of the ability of target anti-damage, the residual penetration method was generally chosen. The ultimate velocity method was selected in this paper.

The $H_{1} / 2$ thickness of each layer of the layered space plates and the $H_{2}$ thickness of homogeneous steel target was penetrated by spherical fragment, and the same $V_{50}$ of ultimate velocity was obtained on two kinds of target, so the total $H_{1}$ thickness of layered space plates and the $H_{2}$ thickness of homogeneous steel was equivalent. The equivalent diagram of layered space plates and homogeneous steel as shown in Fig. 1. 


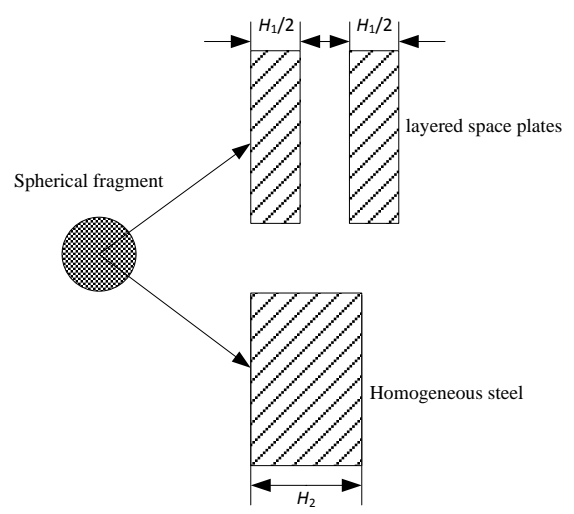

Fig. 1 Equivalent diagram of layered space plates and homogeneous steelc

\section{Numerical simulation}

\section{Geometric modeling}

Experiment for reference to construct equivalent target model, material and size of fragment based on the literature[2], and combining the model shown in Fig. 1: (a)Target model: the materials of spherical fragment was tungsten alloy, the diameter was $10 \mathrm{~mm}$; Target plate was layered space plates, and a total of two layer. The materials of plate was $2 \pi$ armor steel, the size was $100 \mathrm{~mm} \times 100 \mathrm{~mm} \times 3 \mathrm{~mm}$; (b)Equivalent target model: the size and material of fragment was the same as the target model, the materials of the plate was $2 \pi$ armor steel, the size was $100 \mathrm{~mm} \times 100 \mathrm{~mm} \times 6 \mathrm{~mm}$. The constitutive model of fragment was Plastic_Kinematic[3], and the LY12CZ aluminum alloy and $2 \pi$ armor steel was Johnson_Cook[3]. The symmetric plane was applied by boundary conditions, and a quarter of the overall model was used calculated based on the symmetry of the model. The finite element calculation model was shown in Fig. 2.

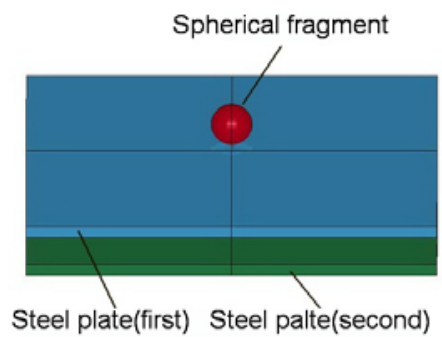

(a) Target model

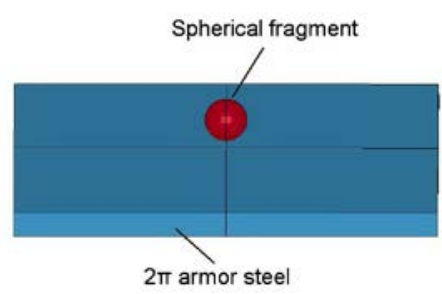

(b) Equivalent target model Fig. 2 Finite element model of calculation

\section{Results and analysis of simulation}

The $10 \mathrm{~mm}$ diameter spherical tungsten alloy fragment with $440 \mathrm{~m} / \mathrm{s}$ and the $450 \mathrm{~m} / \mathrm{s}$ vertically impacted on $6 \mathrm{~mm}$ thickness armor steel plates, the curve and the impact process of the fragment velocity as shown in Fig. 3 and Fig. 4.
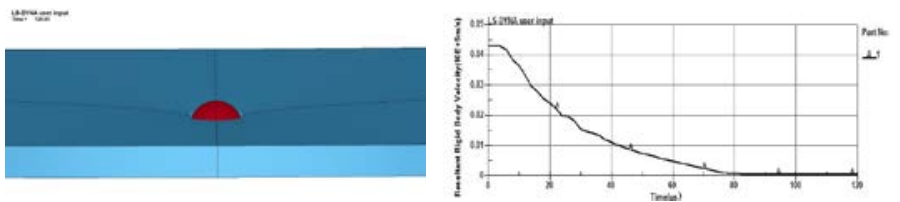

Fig. 3 State and velocity curve of spherical tungsten alloy fragment vertically impacted on $6 \mathrm{~mm}$ thickness armor steel at $440 \mathrm{~m} / \mathrm{s}$
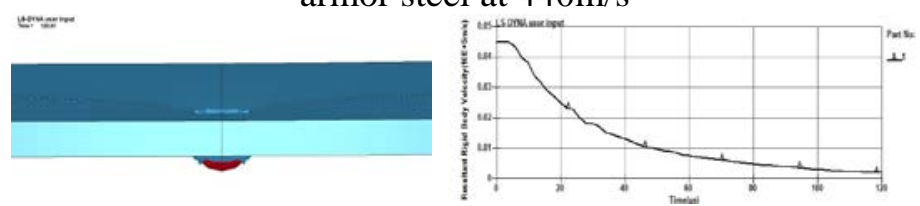

Fig. 4 State and velocity curve of spherical tungsten alloy fragment vertically impacted on $6 \mathrm{~mm}$ thickness armor steel at $450 \mathrm{~m} / \mathrm{s}$ 
As shown in Fig. 3, when the impact velocity was $440 \mathrm{~m} / \mathrm{s}$, $\mathrm{t}=80 \mu \mathrm{s}$, the velocity of tungsten alloy spherical fragment was zero, and the armor steel plate was not penetrated by fragment.

As shown in Fig. 4, when the impact velocity was $440 \mathrm{~m} / \mathrm{s}, \mathrm{t}=120 \mu \mathrm{s}$, the velocity of tungsten alloy spherical fragment was not zero, and the armor steel plate was penetrated by fragment; So, the ultimate velocity of $6 \mathrm{~mm}$ thickness armor steel plates was $450 \mathrm{~m} / \mathrm{s}$ by tungsten alloy spherical fragment.

According to the above method and the fragment's size, plate's thickness in literature[3], 4 kinds of scheme of the numerical simulation were calculated, the results of simulation and the experimental data in literature[3] were compared, as shown in Table 1.

The results of simulation and calculation from the Table 1 were found that the error of numerical simulation and experimental data was small, all within $6 \%$, so the finite element material model, parameters, the algorithm, the results of simulation were all reliable, this model can be used for the calculation of equivalent relationship.

Table 1 Comparison of the simulation and the experiment of the ultimate velocity of armor steel

\begin{tabular}{ccccc}
\hline $\mathrm{H}_{2} / \mathrm{mm}$ & Diameter/mm & Experiment $/ \mathrm{m} / \mathrm{s}$ & Simulation $/ \mathrm{m} / \mathrm{s}$ & error \\
\hline 6 & 7.6 & 606 & 620 & $+2.3 \%$ \\
6 & 10 & 453 & 450 & $-0.6 \%$ \\
10 & 7.6 & 881 & 850 & $-3.5 \%$ \\
10 & 10 & 666 & 710 & $+5.1 \%$ \\
\hline
\end{tabular}

The finite element model(a) for calculation, in the case of 10mm diameter fragment, the ultimate velocity of the different thickness of layered space plates penetrated by fragment was obtained, the results as shown in Table2.

Table 2 The ultimate velocity of different thickness of layered space plates penetrated by $10 \mathrm{~mm}$ diameter fragment

\begin{tabular}{ccc}
\hline$H_{1} / \mathrm{mm}$ & Diameter $/ \mathrm{mm}$ & $V_{1} / \mathrm{m} / \mathrm{s}$ \\
\hline 6 & 10 & 420 \\
7 & 10 & 470 \\
8 & 10 & 540 \\
9 & 10 & 580 \\
10 & 10 & 660 \\
\hline
\end{tabular}

The relationship between the thickness $H_{1}$ and the ultimate velocity $V_{1}$ was fitted without considering the diameter of fragment, the fitted formula as shown in Fig. 5:

$$
V_{1}=59 H_{1}+62
$$

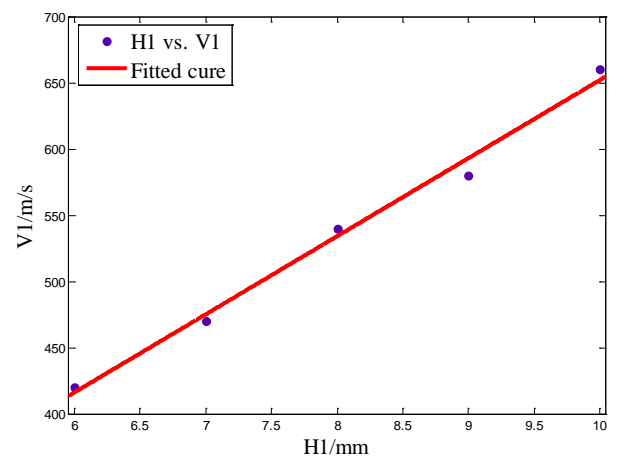

Fig. 5 Diagram of the thickness of layered space plates and the ultimate velocity of fragment

The finite element model(b) for calculation, in the case of $10 \mathrm{~mm}$ diameter fragment, the ultimate velocity of the different thickness of steel plate penetrated by fragment was obtained, the results as shown in Table 3. 
Table 3 The ultimate velocity of different thickness of steel plate penetrated by $10 \mathrm{~mm}$ diameter fragment

\begin{tabular}{ccc}
\hline $\mathrm{H}_{2} / \mathrm{mm}$ & Diameter $/ \mathrm{mm}$ & $V_{2} / \mathrm{m} / \mathrm{s} /$ \\
\hline 6 & 10 & 450 \\
7 & 10 & 490 \\
8 & 10 & 540 \\
9 & 10 & 630 \\
10 & 10 & 710 \\
\hline
\end{tabular}

The relationship between the thickness $H_{2}$ and the ultimate velocity $V_{2}$ was fitted, and the fitted formula as shown in Fig. 6:

$$
V_{2}=66 H_{2}+36
$$

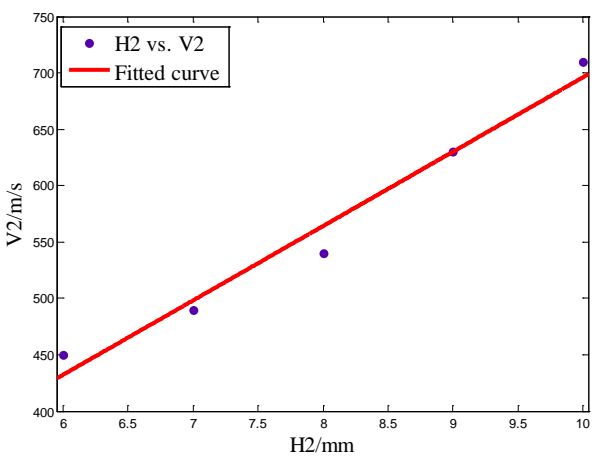

Fig. 6 Diagram of the thickness of steel plate and the ultimate velocity of fragment

The equivalent principle shows that when the ultimate velocity $V_{1}$ and $V_{2}$ were equal, the thickness $H_{1}$ of layered space plates and thickness $H_{2}$ of homogeneous steel were equivalent. Therefore, Through Eq. 1 and Eq. 2, the equivalent relation of the layered space plates and the steel plate penetrated by fragment can be obtained:

$$
H_{2}=0.894 H_{1}+0.394
$$

\section{Conclusion}

Based on the rule that the ultimate velocity, the simulation model of tungsten sphere into layered space plates and homogeneous steel was established, and the ultimate velocity of layered space plates and steel plate penetrated by spherical fragment was obtained through the simulation calculation, and fitted the formula. Based on the equivalent principle and through the Eq. 1 and Eq. 2, the equivalent relations Eq. 3 of layered space plates and steel plate penetrated by fragment was obtained.

\section{Reference}

[1] NIU Xinmin, ZHAI Xiaoli, JIANG Haozheng. An Investigation on the Penetration of Multi-Layered Space Plates of Aluminum Alloy by a Tungsten Sphere[J]. Journal of Beijing Institute of Technology, 1997,17(1):111-116.

[2] XIONG Ran, GAO Xinbao, ZHANG Junkun etc. Simulation on Equivalence between Ceramic and Homogeneous Steel Impacted by Rod Armor-piercing Projectile[J]. Journal of Projectiles; Rockets; Missiles and Guidance, 2013,33(5):102-104.

[3] CAO Bing. An Experimental Investigation on the Equivalent Relation Between Different Armour Plates Penetrated by Fragments[J]. Journal of Projectiles; Rockets; Missiles and Guidance, 2006,26(4):113-117.

[4] WU Yanhong. Numerical Simulation on the Defensive of Ceramic Composite Plate[D]. Beijing: Beijing Institute of Technology,2006.

[5] MI Shuangshan, ZHANG Xien, TAO Guiming. Finite element analysis of spherical fragments penetrating LY_12 aluminum alloy target[J]. Explosion and Shock Waves, 2005,25(5):477-479. 